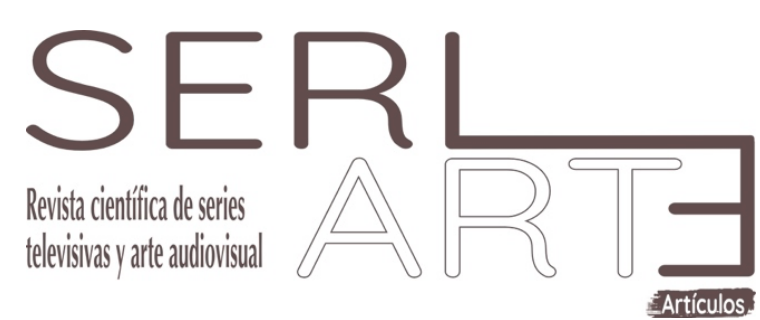

\title{
LOS DOCUMENTALES TURÍSTICOS PARA TELEVISIÓN DE RAMÓN MASATS: PRÉSTAMOS Y ESTRATEGIAS DE HIPERMEDIACIÓN ${ }^{1}$
}

\section{TOURIST DOCUMENTARIES FOR TELEVISION BY RAMÓN MASATS: LOANS AND HYPERMEDIACY}

Lucía Rodríguez García de Herreros

Universidad Carlos III de Madrid

lucrodri@hum.uc3m.es

ORCID https://orcid.org/0000-0001-7686-484X

\section{Resumen}

Las relaciones de hibridación, convergencia o préstamo entre distintos medios ocupan buena parte de las reflexiones sobre los entornos mediáticos de la era digital, pero ¿̇cómo deben analizarse respecto a periodos históricos anteriores? En el presente artículo se estudian los documentales turísticos para televisión que el fotógrafo Ramón Masats dirigió en los años 60 para la serie de TVE Conozca usted España, para ver cómo operan en ellos los préstamos de otros medios y la reflexión sobre estos, así como sobre el hecho de la mediación.

Se analizarán elementos de fotografía, banda sonora y guion, así como la presencia de celebridades, el trasfondo ideológico del comentario, y las diferentes modalidades de documental empleadas. Además, ese análisis se complementará con datos sobre los procesos de producción de estos

\footnotetext{
1 Este artículo se ha realizado con apoyo del proyecto "Cine y televisión en la era del cambio digital y la globalización (1993-2008): identidades, consumo y formas de producción", financiado por la Agencia Estatal de Investigación (referencia PID2019-106459GB-100). 
documentales televisivos, que resultan paradigmáticos de un momento de consolidación y desarrollo que vivía TVE coincidiendo con el arranque de la segunda cadena. Se trata de información extraída de una entrevista personal con Masats. Por último, toda esta información se contextualiza en el marco del boom turístico que las instituciones aprovecharon para promover una nueva imagen de España.

\section{Abstract}

Hybridization, convergence and loans between different media have motivated many reflections on the media environments of the digital age, but are they meaningful when studying previous historical periods? This article is focused on the tourist documentaries for television that Spanish photographer Ramón Masats directed in the 1960s for the TVE series Conozca usted España. The main objective is detecting how loans from other media operate in them, and how the fact of mediation is depicted.

Elements of photography, soundtrack and script will be analyzed, as well as the presence of celebrities, the ideological background of the discourse, and the different modes of documentary used. In addition, this analysis is complemented with data on the production processes of these television documentaries, which are paradigmatic of the moment of consolidation and development that TVE was experiencing during the take-off of its second channel. This information was obtained from a personal interview with the author, Masats. Finally, the context will be crucial: the tourism boom that was used to promote a new image of Spain in the second half of Francoism.

\section{Palabras clave}

Hipermediación; Ramón Masats; Documental turístico; TVE; Boom turístico; Turismo interno.

\section{Keywords}

Hypermediacy; Ramón Masats; Tourist documentary; TVE; Tourism boom; Domestic tourism. 


\section{Introducción}

Transmediación, interactividad, hibridación, inmediatez, hipermediación... son algunos de los términos con los que se han venido caracterizando entornos y obras audiovisuales de la era digital. No obstante, es sabido que algunos de esos conceptos pueden aplicarse también a momentos históricos previos: por ejemplo, algunos autores han puesto de relieve cómo la idea de transmedia es útil para evaluar la circulación de un mismo mensaje o universo de mensajes a través de diferentes medios del siglo XX (Rueda Laffond, 2018: 104).

Este artículo pretende analizar la producción de un director y un programa significativos de la televisión española de los años 60, para detectar si se le puede aplicar la idea de hipermediación ${ }^{2}$ y de qué modo. Así, los resultados apuntarán si, en el caso de la televisión española, tiene sentido o no abrir la cronología más allá de la contemporaneidad digital a la hora de usar conceptos teóricos como este (y en qué medida, con qué orientación, en relación con qué particularidades contextuales...).

Conozca usted España (TVE, 1966-1969) fue una serie documental de TVE. SU principal meta era la promoción del turismo interno, y habitualmente cada episodio se focalizaba en una ciudad o ruta, presentada a los espectadores por un famoso relacionado de una $u$ otra forma con el asunto tratado. Su coordinador, Salvador Pons, era en ese momento uno de los principales responsables del desarrollo de la recién nacida segunda cadena de TVE (si bien la mayoría de los episodios de esta serie se estrenaron en el primer canal, en horario nocturno).

En su momento, Conozca usted España fue uno de los programas de producción propia más importantes realizados por TVE. Cosechó buenas críticas y superó ampliamente los cuatro millones de espectadores de media (Palacio, 2008: 70). Se ha sugerido que este programa puede considerarse hito y modelo para otros espacios televisivos de los siguientes años por sus posibles

\footnotetext{
2 Entendemos hipermediación (la lógica que visibiliza explícitamente la presencia de múltiples mediaciones) en términos de Bolter y Grusin (1999), tal y como se desarrollará en el apartado correspondiente al marco teórico.
} 
LUCÍA RODRÍGUEZ GARCÍA DE HERREROS

LOS DOCUMENTALES TURÍSTICOS PARA TELEVISIÓN DE RAMÓN MASATS: PRÉSTAMOS Y ESTRATEGIAS DE HIPERMEDIACIÓN

aportaciones a un nuevo canon televisivo y un nuevo modelo de producción (Palacio, 2000: 30-33), y, desde luego, puede catalogarse como ejemplo pionero del auge del formato documental detectado por Antona (2016: 13-14) en su estudio de la parrilla del tardofranquismo.

Además de esas justificaciones principalmente industriales, otro aspecto destacado para escoger Conozca usted España es la autonomía que el programa dio a sus directores, mayoritariamente egresados de la Escuela Oficial de Cinematografía y que, como subraya Fernández, aportarían al programa «la novedad y la dosis de experimentación suficiente hasta convertirla en punto de referencia de la labor televisiva» (2014: 56). Es esta una característica presente en otros programas de TVE de la época, y que ha permitido evaluar la programación durante el franquismo como cadena de transmisión de pensamiento del régimen, pero, a la vez, testeo permanente de los límites de lo permitido3. Es por ello que se considera que un punto de partida autoral puede servir para enriquecer el análisis de la producción de la serie.

Por los cincuenta capítulos de Conozca usted España pasaron casi una veintena de realizadores, muchos, como se ha dicho, procedentes de la Escuela Oficial de Cine (Pedro Olea, José Luis Borau, Mario Camus...). Sin embargo, el director que dirigió más capítulos fue el fotógrafo y documentalista Ramón Masats, que firmó hasta siete episodios y que mantuvo una estrecha relación con el coordinador, Salvador Pons, a quien incluso recomendó otros directores (Palacio, 2000: 34).

Así, esta investigación queda configurada en torno a la siguiente pregunta: ¿qué elementos de hipermediación se detectan en la producción de Ramón Masats para la serie Conozca usted España? ¿̇Es pertinente el uso de ese término, especialmente ligado a los entornos online, para el análisis de esta producción?

A modo de breve estado de la cuestión, valga apuntar que la obra fotográfica de Masats ha sido ampliamente analizada desde la academia: se destaca frecuentemente su valor de documento social (y en ocasiones antropológico)

\footnotetext{
${ }^{3}$ En este sentido, es interesante la síntesis propuesta por Rueda Laffond: «TVE sirvió de caja de resonancia del imaginario tardofranquista, dirigiéndose a apuntalar los consensos sociales [...]. Pero, al mismo tiempo, la pequeña pantalla coadyuvó en la superación de tales consensos, facilitando el desmontaje institucional y simbólico del régimen que le sirvió de placenta» (2015: 4147).
} 
de la España de su tiempo, así como su inscripción en una generación que superó la fotografía pictoralista imperante tras la Guerra Civil (López Mondéjar, 2010; Panero García, 2020). Algunos estudios recientes han señalado además cómo en ocasiones el trabajo de edición de los fotolibros en que participó Masats, por el cuál él mismo mostró interés, puede considerarse emparentado con algunos recursos audiovisuales como el racord (Fuster, 2017: 645).

Pero no solo se han detectado algunas resonancias audiovisuales en su fotografía, sino que la obra audiovisual de Ramón Masats ya ha sido sometida a un examen exhaustivo en el monográfico Ramón Masats: Ibèria inèdita, dirigido por Josetxo Cerdán, cuya introducción señala cómo, además de por su intuición y su independencia, la obra de Masats es interesante por unir lo mejor de dos tradiciones cinematográficas de la época que a veces se han considerado excesivamente contrapuestas: una realista asociada a Madrid y otra vanguardista ligada a Barcelona (Cerdán, 2000: 10).

En ese volumen se recoge también un listado de trabajos para TVE del fotógrafo (Sánchez Salas, 2000), que participó entre otras series en La víspera de nuestro tiempo (TVE, 1967-1969), Íntima armonía (TVE, 1971-1972), Si las piedras hablaran (TVE, 1972-1973), Los ríos (TVE, 1974-1975), además de en Conozca usted España. Así, queda claro que Masats fue una figura relevante en televisión en los últimos años del franquismo.

\section{Metodología}

En sintonía con el enfoque y objetivos adoptados, se propone una metodología mixta constituida por:

1) el análisis textual/de la imagen sobre los episodios de Conozca usted España dirigidos por Ramón Masats (abarcando imagen, palabra y música). La selección de los capítulos se verá previsiblemente condicionada por criterios de accesibilidad. Aun así, Masats continúa siendo el director de la serie del que es posible visionar más episodios en los archivos disponibles, junto a César Fernández Ardavín, del que hay igualmente seis capítulos disponibles. 
LUCÍA RODRÍGUEZ GARCÍA DE HERREROS

LOS DOCUMENTALES TURÍSTICOS PARA TELEVISIÓN DE RAMÓN MASATS: PRÉSTAMOS Y ESTRATEGIAS DE HIPERMEDIACIÓN

2) la conversación con el director, para esclarecer algunos avatares de la producción, sus intereses estéticos, su concepción del documental... partiendo de la premisa de que se benefició de niveles elevados de autonomía, como se ha explicado anteriormente. A partir de un cuestionario de preguntas abiertas, se han tratado de abordar los siguientes temas en relación a Conozca usted España: directrices de la serie; visión personal del proyecto; influencias; temas; procesos de preproducción, rodaje y postproducción.

\section{Marco teórico}

La hipermediación, en términos de Bolter y Grusin (1999: 20-86), es una lógica por la que la experiencia de la comunicación subraya su cualidad mediada, es decir, se explicita la presencia del medio. Se construye, por tanto, en oposición a la inmediatez, de la cual el mayor exponente es quizá la realidad virtual, pero que puede detectarse en la pintura en perspectiva y en todas aquellas formas de representación que nos invitan a olvidar el hecho de la mediación y sumergirnos en lo representado. El ejemplo más recurrente de construcción hipermediada es el funcionamiento mediante ventanas de las interfaces de ordenador: se trata de una forma de ordenar la mediación que no crea un espacio unificado, sino heterogéneo, y que hace visibles explícitamente los diferentes actos de representación (Bolter y Grusin, 1999: 33-34).

Para Bolter y Grusin, hipermediación e inmediatez son dos caras de la misma moneda; en su opinión, la cultura global contemporánea «wants both to multiply its media and to erase all traces of mediation: ideally, it wants to erase itself in the very act of multiplying them $\rangle^{4}$ (1999: 5). En ese proceso, sostienen, es fundamental que premisas o lógicas de representación salten de un medio a otro (por ejemplo, las influencias y préstamos de la pintura en la fotografía y viceversa, de los videojuegos en el cine y viceversa, etc.).

Estas dos lógicas son entendidas por los autores en dos sentidos diferentes: uno epistemológico y otro psicológico. En el caso de la hipermediación, el sentido epistemológico se relaciona con «the fact that knowledge of the world comes

\footnotetext{
${ }^{4}$ «Quiere multiplicar los medios y a la vez eliminar todo rastro de mediación: idealmente, quiere hacerse invisible en el propio acto de multiplicarsen.
} 
LUCÍA RODRÍGUEZ GARCÍA DE HERREROS

LOS DOCUMENTALES TURÍSTICOS PARA TELEVISIÓN DE RAMÓN MASATS: PRÉSTAMOS Y ESTRATEGIAS DE HIPERMEDIACIÓN

to us through media. The viewer acknowledges that she is in the presence of a medium and learns through acts of mediation» ${ }^{5}$ (Bolter y Grusin, 1999: 70-71), mientras que el psicológico tiene que ver con «the insistence that the experience of the medium is itself an experience of the realı/ (Ibidem).

Los autores señalan que el interés por la hipermediación se ha exacerbado en la era de Internet, pero que no es exclusivo de esta. Algunos antiguos ejemplos de hipermediación son las miniaturas de los manuscritos iluminados, en los que ilustración y escritura se funden en un mismo diseño, o las catedrales medievales, en las que la suma de elementos escultóricos, arquitectónicos y pictóricos en un mismo espacio multiplica la conciencia que tiene el visitante de los diferentes canales artísticos. Aun así, Bolter y Grusin aclaran que no consideran la hipermediación o la inmediatez como lógicas universales, sino «practices of specific groups in specific timesı7 $(1999: 21)$, por lo que se hace relevante ir al caso cuando se adapta una perspectiva histórica, y analizar las particularidades de cada medio en su época.

La televisión ha tenido desde sus orígenes importantes lazos con la idea de hipermediación: tomó préstamos de otros medios desde que apareció, prescindió del fotorrealismo, aunque incorporando una suerte de realismo ideológico, ha popularizado formatos tan indiscutiblemente hipermediados como el anuncio y ha fomentado la fascinación por el propio medio televisivo de forma totalmente explícita (Bolter y Grusin, 1999: 186-194).

La España de los años 60 puede servir como ejemplo de algunas de estas prácticas, con la particularidad de que, como veremos, las lógicas de hipermediación son coherentes, además, con la trayectoria y formas de producción de algunos realizadores pioneros de la televisión.

\section{Resultados}

Para ver los episodios dirigidos por Ramón Masats para Conozca usted España, se ha accedido al Archivo ARCA de RTVE. En él, se conservan seis de los siete

\footnotetext{
5 «El hecho de que el conocimiento del mundo nos llega mediado. El espectador reconoce estar en presencia de un medio, y aprender a través de actos de mediación».

6 «La insistencia en que la experiencia del medio es en sí misma experiencia de lo real».

7 «Prácticas de grupos específicos en momentos específicos».
} 

HIPERMEDIACIÓN

capítulos que dirigió Masats. La información disponible en esos mismos audiovisuales, combinada con la Hemeroteca $A B C$ en su sección de programación televisiva, arroja la siguiente información sobre dichos episodios:

\begin{tabular}{|c|c|c|c|c|}
\hline Título & Guion & Presentador & Operador & Estreno \\
\hline Las Ramblas & $\begin{array}{l}\text { Gonzalo } \\
\text { Suárez }\end{array}$ & Nuria Espert & $\begin{array}{c}\text { Juan Manuel } \\
\text { de la Chica } \\
\text { (ayudante: } \\
\text { Emilio García } \\
\text { de Castro) }\end{array}$ & $\begin{array}{c}\text { 6-5-66, 23.00 } \\
\text { La } 1\end{array}$ \\
\hline $\begin{array}{c}\text { La Casa de } \\
\text { Alba }\end{array}$ & $\begin{array}{l}\text { José Antonio } \\
\text { Pita Andrade }\end{array}$ & $\begin{array}{c}\text { Duquesa de } \\
\text { Alba }\end{array}$ & $\begin{array}{c}\text { Sin } \\
\text { información }\end{array}$ & $\begin{array}{c}\text { 17-6-66, } \\
\text { 22.45, La } 1\end{array}$ \\
\hline $\begin{array}{l}\text { Canto a la } \\
\text { Andalucía } \\
\text { musulmana }\end{array}$ & Miguel Rubio & $\begin{array}{l}\text { Noha Al- } \\
\text { Hegelan, } \\
\text { embajadora } \\
\text { de Arabia } \\
\text { Saudita }\end{array}$ & $\begin{array}{c}\text { Hans } \\
\text { Burmann } \\
\text { (ayudantes: } \\
\text { Nicolás } \\
\text { Redondo, } \\
\text { Tomás Mas) }\end{array}$ & $\begin{array}{c}5-9-66,23.00 \\
\text { La } 1\end{array}$ \\
\hline $\begin{array}{l}\text { Embajada } \\
\text { española en } \\
\text { Washington }\end{array}$ & Miguel Rubio & $\begin{array}{l}\text { Marquesa de } \\
\text { Merry del Val }\end{array}$ & $\begin{array}{c}\text { Sin } \\
\text { información }\end{array}$ & $\begin{array}{c}\text { 9-12-66, } \\
\text { 23.15, La } 1\end{array}$ \\
\hline Salamanca & Luis Cortés & $\begin{array}{c}\text { María José } \\
\text { Alfonso }\end{array}$ & $\begin{array}{l}\text { Juan Manuel } \\
\text { de la Chica } \\
\text { (ayudante: } \\
\text { Emilio García } \\
\text { de Castro) }\end{array}$ & $\begin{array}{c}\text { 14-9-67, } \\
\text { 23.00, La } 1\end{array}$ \\
\hline Lanzarote & $\begin{array}{l}\text { Ramón } \\
\text { Masats }\end{array}$ & $\begin{array}{c}\text { Subdirector } \\
\text { de ventas de } \\
\text { Iberia }\end{array}$ & $\begin{array}{l}\text { Juan Manuel } \\
\text { de la Chica } \\
\text { (ayudante: } \\
\text { Emilio García } \\
\text { de Castro) }\end{array}$ & $\begin{array}{l}\text { 19-4-68, } \\
\text { 23.15, La } 1\end{array}$ \\
\hline
\end{tabular}

Tabla 1. Capítulos de Ramón Masats para Conozca usted España accedidos para la presente investigación. Elaboración propia. Fuentes: Archivo ARCA de RTVE, Hemeroteca ABC.

Del séptimo capítulo, "El toro de lidia", existe una copia en Filmoteca Española, con dificultades de acceso por motivos de formato (fotoquímico). Existen también evidencias de su emisión, como por ejemplo una crítica en ABC Madrid (17-8-69, p. 50). Se ha prescindido de su análisis debido a la imposibilidad de acceso al material. 
LUCÍA RODRÍGUEZ GARCÍA DE HERREROS

LOS DOCUMENTALES TURÍSTICOS PARA TELEVISIÓN DE RAMÓN MASATS: PRÉSTAMOS Y ESTRATEGIAS DE HIPERMEDIACIÓN

\subsection{Avatares de producción}

Ramón Masats realizó sus primeras incursiones en el audiovisual con documentales aparecidos en 1965: Prado vivo (Ramón Masats, 1965), perteneciente a la serie Imágenes de NO-DO) o El que enseña (Ramón Masats, 1965). En estos títulos, comenzó a trabajar con el operador curtido en NO-DO Juan Manuel de la Chica, cuya colaboración continuada se prolongó en proyectos para diferentes casas, tanto NO-DO y TVE como otras. Masats asegura que, al trabajar para TVE, fue él mismo quien habitualmente pidió trabajar con de la Chica, puesto que era un cámara «acostumbrado al reportaje»8. Lo consiguió muchas veces, y consideró a este profesional la constante de su equipo de trabajo: «tenía un buen equipo, sobre todo comandado por Juan Manuel de la Chica».

Como se ha adelantado anteriormente, el sistema de producción de Conozca usted España dejaba un margen de libertad al director. En conjunto, Masats afirma sobre su paso por el proyecto coordinado por Pons que los responsables «eran flexibles, me dejaban hacer». Esto da idea de la forma de organización de las producciones en TVE hacia finales de los 60, que Manuel Palacio (2000: 33) ha caracterizado mencionando la importancia del coordinador (figura similar a la del productor), los encargos puntuales a ciertos realizadores que gozaban de autonomía y podían elegir a su equipo en buena medida, y la revisión censora solo a posteriori.

Por otra parte, desde el punto de vista de la producción, hay que aclarar que muchos capítulos de Conozca usted España reconocen explícitamente la participación de productoras externas a TVE, como ocurre en el caso de Cinecorto, especialmente citada en capítulos dirigidos por José Luis Borau ("Zaragoza es algo más", "Lección de Toledo"...), o como sucede con algunos capítulos dirigidos por César Fernández Ardavín, estrechamente vinculados a su productora, Aro Films ("Gastronomía española", "Una copa de vino español"...). También la participación de Masats en Conozca usted España estuvo asociada, puntualmente (como, por ejemplo, en el capítulo "Embajada española en Washington"), a la productora X Films, como indican Cerdán y Fernández- 
LUCÍA RODRÍGUEZ GARCÍA DE HERREROS

LOS DOCUMENTALES TURÍSTICOS PARA TELEVISIÓN DE RAMÓN MASATS: PRÉSTAMOS Y ESTRATEGIAS DE HIPERMEDIACIÓN

Labayen (2012). Se trataba de una productora prolija en cortometrajes que compaginó encargos comerciales con iniciativas vanguardistas relacionadas con las inclinaciones al mecenazgo de su fundador, Juan Huarte (Cerdán y Fernández-Labayen, 2012: 169).

Ese ecosistema de pequeñas productoras que trabajaron para TVE es una interesante muestra de la diversificación del panorama audiovisual español en los años 60, en el que, aunque muchas líneas no tuvieran continuidades claras, existieron diferentes oportunidades de realizar proyectos que iban más allá del puro interés comercial.

Este ecosistema de producción de documentales de corte turístico encargados desde TVE contó, en ocasiones, con oportunidades fuera del alcance de los productores más pequeños, tanto por los medios económicos disponibles como por la óptima disposición de las autoridades. Por ejemplo, los títulos de crédito del capítulo "Lanzarote" incluyen un agradecimiento a César Manrique y Juan Brito por su colaboración, y también al Ministerio del Aire «por la colaboración que sus helicópteros han prestado para el rodaje de este documentalı. Los planos aéreos eran el recurso estrella de los documentales turísticos con más medios, y a menudo constituían el hilo conductor de estas películas, como en los títulos Viaje fantástico en globo (César Fernández Ardavín, 1964) o Memorias de un pájaro (César Fernández Ardavín, 1971).

Resulta llamativo que, pese a que algunos capítulos contaran con esa relativa abundancia de medios, Masats recuerde que «no había dinero para ir a localizar y luego rodarı, lo que hacía que documentos como el guion fueran flexibles. «No localizábamos, pero sí nos informábamos a través de libros», afirma el autor.

Esta forma de trabajar nos puede remitir a una capa extra de mediación en la producción, que recuerda, salvando las distancias, a la que se da en los propios visitantes, que consultan fuentes como las guías turísticas antes de un viaje. Como han desarrollado extensamente los tourism studies, la mirada del turista es una mirada cargada de expectativas, que, en muchas ocasiones, busca reconocer en su visita aquello que ha anticipado a través de guías, folletos o postales (Urry y Larsen, 2011). 
LUCÍA RODRÍGUEZ GARCÍA DE HERREROS

LOS DOCUMENTALES TURÍSTICOS PARA TELEVISIÓN DE RAMÓN MASATS: PRÉSTAMOS Y ESTRATEGIAS DE HIPERMEDIACIÓN

\subsection{Elementos para el análisis}

\subsubsection{Modalidad documental, celebridades impuestas y comentarios de tesis}

Como puede comprobarse, pese al predominio de los temas turísticos, dos de los seis capítulos recopilados son excepcionalmente interesantes para el análisis desde un punto de vista político debido a su temática: "La Casa de Alba" y "Embajada española en Washington". A ellos, hay que sumar "Canto a la Andalucía musulmana", en el cual no es tanto la temática como la presentadora lo que despierta el interés desde esta perspectiva9. Para entender el porqué de estas conexiones políticas y la plena sintonía de la serie con el Ministerio de Información y Turismo, hay que recordar que su coordinador, Salvador Pons, había sido jefe de la sección de publicaciones de dicho organismo.

Es sabido que la campaña "XXV Años de Paz" de 1964 insufló un nuevo espíritu al discurso del régimen, promovido por el máximo responsable del gobierno en materia de comunicación, Manuel Fraga Iribarne. El aperturismo, el optimismo y la celebración del desarrollo fueron algunos de sus principales vectores, compartidos en buena medida por un proyecto como Conozca usted España.

Sin embargo, recordamos de nuevo que el esquema de producción de la serie otorgaba libertad al director (la modernidad buscada se presuponía en la mirada de una cantera de directores mayoritariamente jóvenes); el único aspecto en que es abiertamente reconocida y explícita la intervención de superiores en la realización es justamente en la selección de los presentadores. Fue «una exigencia de TVE (...) poner a alguna gente conocida que incentivara más el interés del documental», explica Masats, considerándola prácticamente la única imposición en todo el proceso de rodaje.

Respecto a la actuación de estas celebridades, se detectan en varios casos discursos de tesis a través del comentario del presentador, si bien Masats afirma no haber intervenido particularmente en este sentido. Los capítulos se componen de un modo eminentemente expositivo, complementado con entrevistas (modo interactivo), modos de representación que facilitan y

\footnotetext{
9 El capítulo se rueda coincidiendo con el viaje de Manuel Fraga Iribarne a Arabia Saudí, uno de los movimientos de acercamiento más interesantes de España en sus relaciones internacionales del periodo.
} 
LUCÍA RODRÍGUEZ GARCÍA DE HERREROS

LOS DOCUMENTALES TURÍSTICOS PARA TELEVISIÓN DE RAMÓN MASATS: PRÉSTAMOS Y ESTRATEGIAS DE HIPERMEDIACIÓN

subrayan esa tendencia a disponer argumentos hacia una determinada idea. También existen puntuales elementos performativos relacionados con los presentadores, y, en alguna rara ocasión, hay secuencias que pueden adscribirse al modo observacional10.

El capítulo "Lanzarote" cuenta con una presencia muy débil y poco marcada, casi invisible, del cicerone, mientras que el episodio "Salamanca" apenas hila argumentos, aunque sí se beneficia del carisma de su presentadora, María José Alfonso, quien, desde lo performativo, acompaña al espectador por la ciudad en calidad de visitante y estudiante, hasta el punto de que despide el capítulo desde un dormitorio en el que simula estudiar.

Los otros cuatro capítulos sí incluyen tesis más marcadas en sus guiones. Por ejemplo, los comentarios de Nuria Espert perfilan un discurso muy coherente sobre Barcelona en el capítulo "Las Ramblas". "Esta gran ciudad siempre ha sabido estar a tono con su tiempo. Y ha sabido armonizar el culto al arte con las chimeneas de las fábricası, dice al principio, resumiendo el contenido que se desarrollará a continuación. Esta idea se ve muy reforzada por el espíritu de sinfonía urbana del capítulo, que presenta una ciudad diversa y trepidante, en la que conviven todos los opuestos en un entorno cosmopolita.

"La casa de Alba" es un retrato de dicha institución, en el cual destaca la preferencia por el modo interactivo: el capítulo se estructura mediante entrevistas a la familia y su servicio. Entre ellas, destaca la realizada a la duquesa Cayetana de Alba, que describe su rutina (actividades benéficas, hípica, conciertos...) para sostener la tesis central, en línea con el aire de los tiempos ${ }^{11}$, de que la suya es una vida normal:

Yo no sé por qué hay que pensar que somos diferentes a las demás personas. Quizás tengamos más obligaciones o más posibilidades que otros, pero yo creo que debemos... pues trabajar y ayudar y hacer todo lo que podemos, igual que todo el mundo debe hacer en esta vida actual.

Algún punto en común con este discurso tiene la aparición en otro capítulo de la marquesa de Merry del Val, esposa del embajador español en Washington. Al mostrar la actividad de la embajada, la marquesa sugiere que se trabaja

\footnotetext{
10 Terminología tomada de la clásica categorización de Nichols (2013) sobre los modos del documental. 11 Poco después, la BBC estrenó el documental Royal family (Richard Cawston, 1969), con parecido espíritu desmitificador.
} 
LUCÍA RODRÍGUEZ GARCÍA DE HERREROS

LOS DOCUMENTALES TURÍSTICOS PARA TELEVISIÓN DE RAMÓN MASATS: PRÉSTAMOS Y ESTRATEGIAS DE HIPERMEDIACIÓN

incesantemente, preparando el terreno para la tesis central, que corroboran diferentes periodistas estadounidenses entrevistados hacia el final del episodio: la imagen de España en Estados Unidos ha mejorado significativamente en los últimos años.

Por su parte, la embajadora saudí Noha Al-Hegelan propone una revisitación de todos los lazos de unión entre Andalucía y el mundo musulmán, a través de argumentaciones étnicas, culturales o históricas: «mucho se ha hablado de la influencia racial árabe sobre los españoles, pero es este un tema muy polémico sobre el que no se ponen de acuerdo los especialistas», o «Andalucía, quizá más Oriental que europea, tiene estos rincones misteriosos donde a veces se tiene la impresión de que, de un momento a otro, va a oírse el canto del almuédano llamando a oración o la recitación de un zéjel», o bien «ocho siglos de permanencia arraigan mucho. A veces, conviene recordar que estos seres de distinta religión no eran realmente extranjeros». Resulta interesante y algo forzada su ambigua construcción de un «nosotros» que hace referencia a los españoles («nuestros antepasados los moros», «nos trajeron los limoneros y naranjosı, etc.).

Se puede detectar cierta tendencia al perspectivismo (y al interés por la modalidad interactiva, tan en boga entonces) a la hora de sostener estas tesis. Las palabras de Espert en "Las Ramblas" se pueden cotejar con entrevistas a un limpiabotas, una vendedora de flores de la Boquería o el conserje del Palacio de la Virreina; las de la duquesa, con las de su servicio; las de la marquesa, con las de los periodistas americanos, y las de la embajadora Al-Hegelan, con las de un filólogo experto en arabismos, un arqueólogo de Medina Azahara o con Félix Rodríguez de la Fuente, que aparece en tanto que experto en cetrería, práctica vinculada a Al Andalus.

\subsubsection{Fotografía, música y montaje}

La claridad expositiva fue una de las principales preocupaciones de Ramón Masats. A su parecer, Conozca usted España «tenía mucho más de didáctico que de conceptual». Siguiendo ese punto de partida, el fotógrafo confirma que en su trabajo fue relevante una idea: «el tópico fue muy importante. Y el 
LUCÍA RODRÍGUEZ GARCÍA DE HERREROS

LOS DOCUMENTALES TURÍSTICOS PARA TELEVISIÓN DE RAMÓN MASATS: PRÉSTAMOS Y ESTRATEGIAS DE HIPERMEDIACIÓN

"contratópico", [cuando] una cosa dentro del tópico quería explicar otra», añade.

En el caso de Conozca usted España, existen numerosos tropos o composiciones que remiten al mundo que encumbró a Masats, el de la fotografía. Para la fecha de estreno de la serie, Masats ya había publicado varios fotolibros, y en algunos de ellos reluce el interés por la idea de tópico o la de tradición: Los sanfermines (1963), Viejas historias de Castilla la vieja (1964) ... Así, no sorprende que en ocasiones surjan en las imágenes audiovisuales de Masats reminiscencias de hitos de la fotografía de su época.

Como ejemplo de genealogía en este sentido, se puede citar el momento de "Las Ramblas" en que el capítulo hace una descripción de la vida nocturna. «En algunas esquinas se han pedido besos, o se han comprado, bajo la mirada de desaprobación de las gentes de bienı, dice en off Nuria Espert, mientras suena música pop-rock ("Day tripper", "Satisfaction", "Mejor" ...) y el plano muestra a dos hombres en uniforme de marinero, caminando de espaldas.

El propio Masats ya había realizado en los 50 una investigación sobre las Ramblas y el centro de Barcelona, y otros autores cuyos foto-reportajes continúan siendo igualmente icónicos, como Francesc Català-Roca (famosa es su fotografía de dos marineros de espaldas acompañados de dos prostitutas) o Xavier Miserachs, habían explorado temáticas como el piropo o la prostitución en la Barcelona de los 50-60, representadas en Conozca usted España en su versión menos sórdida.

La mejor técnica para dulcificar estas realidades es el montaje: los marineros y la alusión a «comprar» besos se acompañan de música alegre, y van precedidos de un rápido montaje de neones, actuaciones y camareros de las salas de baile. Todo ello impregna las actividades del Raval de un aura festiva. La acumulación se presenta, así, como una herramienta para transformar lo realista, costumbrista o hasta naturalista en pintoresco, de acuerdo a los estándares del visitante: se trata casi de una versión turística del montaje de atracciones.

Por otra parte, cabe recordar que algunas de esas imágenes y retratos se inscriben en recorridos iconográficos que se retrotraen mucho más allá de los grandes autores de fotografía de los 50. En el mismo capítulo sobre Barcelona, 
LUCÍA RODRÍGUEZ GARCÍA DE HERREROS

LOS DOCUMENTALES TURÍSTICOS PARA TELEVISIÓN DE RAMÓN MASATS: PRÉSTAMOS Y ESTRATEGIAS DE HIPERMEDIACIÓN

los numerosos planos del limpiabotas entrevistado remiten a la trayectoria de este oficio como icono urbano relacionado con el mundo de la picaresca, como señala Fuentes Vega (2017: 179-184). Se trata, explica la autora, de una figura menos incómoda que el mendigo para el régimen, pero igualmente pintoresca para el visitante extranjero, quien tendía a romantizar la pobreza que encontraba en España gracias a la comparación con hitos de la historia del arte español (por ejemplo, cuadros del Siglo de Oro, como los de Murillo), e incluía en sus descripciones y fotografías de viaje retratos de algunos oficios callejeros.

Además de las relaciones y los préstamos ya citados en relación al mundo de la fotografía o la pintura, una constante en el audiovisual de interés turístico son las vistas turísticas, emparentadas con el género paisajístico fotográfico (y en especial con las postales) o pictórico: grandes planos generales relativamente previsibles a nivel compositivo, fijos o acompañados de un lento paneo horizontal, que en los documentales sirven para ubicar al espectador, junto a los planos de situación compuestos con los monumentos más representativos de un determinado lugar. En términos generales, Masats huye de este tipo de composiciones en Conozca usted España. En el capítulo presentado por Nuria Espert, por ejemplo, el planteamiento metonímico sobre el cosmopolitismo de Barcelona (el hecho de tomar solo las Ramblas como referente) convierte en innecesaria la panorámica de la ciudad con vocación de totalidad.

Este será un planteamiento recurrente: muchos de los capítulos de Masats parecen buscar una esencia de los lugares visitados a través de un examen de sus partes, de un procedimiento más analítico que sistemático. Por citar solo otro ejemplo, el capítulo "Salamanca" lo abren obreros picando piedra en la cantera de Villamayor. María José Alfonso recalca que de ahí «han salido durante siglos los bloques de piedra blanda» con que se construyó la ciudad. Propuesta alejada de una posible apertura mediante vista turística, que hubiera podido mostrar la ciudad, presidida por la catedral, desde el otro lado del Tormes, mostrando su caudal y un puente. Es un plano como este el que nos introduce en Salamanca en el capítulo de Conozca usted España "La ruta de la plata", dirigido por Jesús Fernández Santos.

Así, resulta sintomático de la voluntad de dinamismo de Masats el hecho de que en el documental de una ciudad tan monumental como Salamanca 
LUCÍA RODRÍGUEZ GARCÍA DE HERREROS

LOS DOCUMENTALES TURÍSTICOS PARA TELEVISIÓN DE RAMÓN MASATS: PRÉSTAMOS Y ESTRATEGIAS DE HIPERMEDIACIÓN

aparezcan un travelling desde un vehículo o un montaje de retratos en el mercado. Puede considerarse que el interés del fotógrafo en lo que él denomina «tópico» no siempre coincide con los clichés del documental turístico de su tiempo.

En este sentido, es excepcional el capítulo "Embajada española en Washington", el único de la serie Conozca usted España rodado fuera de las fronteras españolas. Los planos de situación de la capital estadounidense cumplen aquí una función necesaria, y las preocupaciones estéticas del episodio, dada su particular finalidad, pasan desapercibidas entre las entrevistas al personal diplomático.

"Canto a la Andalucía musulmana" sí incluye diferentes vistas generales de los pueblos blancos, pero la forma principal de caracterizarlos no es a través de la panorámica sobre esos conjuntos de arquitectura popular, sino que son los planos más cerrados de callejuelas, pasajes, arcos, celosías y patios. Muy en especial, se da espacio a la ventana enrejada, de reminiscencias orientalistas y que remite a la práctica del cortejo, de la mujer encerrada tras las rejas (Fuentes Vega, 2015: 323-324). La tradición de este tipo de imágenes para ilustrar Andalucía es fértil, y el propio Masats participó con fotografías similares para numerosos folletos turísticos editados por aquellos años, como "Ruta de los pueblos blancos" o "Costa de la Luz" (editados ambos en 1973 por la Dirección General de Promoción del Ministerio de Información y Turismo) 12. "Canto a la Andalucía musulmana" incluye también un expresivo collage de retratos: primeros planos y planos detalle de ojos o bocas que ríen sirven para sugerir, sin que se alcance ninguna conclusión, las supuestas particularidades étnicas de los andaluces.

Y es que, como parece inevitable, Masats aplicó en Conozca usted España algunas de sus preferencias como fotógrafo. Ese parece ser el caso de sus interesantes retratos, llamativos en casi todos sus capítulos. En el contexto de obras utilizadas para la propaganda turística, es pertinente la observación de Fuentes Vega respecto al uso del retrato de habitantes: «si la gran urbe se critica por su despersonalización, la humanización de la misma pasará por resaltar su

12 Folletos accedidos en el archivo del Centro de Documentación Turística de España. 
LUCÍA RODRÍGUEZ GARCÍA DE HERREROS

LOS DOCUMENTALES TURÍSTICOS PARA TELEVISIÓN DE RAMÓN MASATS: PRÉSTAMOS Y ESTRATEGIAS DE HIPERMEDIACIÓN

componente de vitalidad humana. Esto se logra, en primer lugar, captando esas mismas avenidas [...] pero concentrándose en las multitudes de peatones» (2015: 463). Es por medio de los retratos de locales como la ciudad castiza desplaza a la ciudad moderna, a veces poco adecuada para atraer visitantes.

Es interesante constatar cómo en el ámbito audiovisual es posible explicitar aún más el punto de vista desde el que se ha tomado el retrato en cuestión; por ejemplo, mediante contrastes entre la imagen y la banda sonora. Al comienzo del episodio "La casa de Alba", un zoom in nos dirige al interior del Palacio de Liria, donde la duquesa asiste a un recital de música de cámara que se encuentra en segundo plano sonoro mientras la voz en off recita la larga sucesión de títulos y prebendas asociados a la aristócrata. La expresión ligeramente aburrida de la protagonista, que parece aludir tanto al concierto como a sus títulos, crea un efecto irónico.

En el capítulo "Lanzarote", los retratos de las agricultoras de la isla, ataviadas con los trajes típicos y tradicionales sombreros de paja, se acompañan de música moderna, evidenciando la distancia entre ambos lados de la cámara, y contribuyendo a una estilización de atuendos y prácticas que, leídos desde fuera, resultan exóticos (y el hecho de mirarlos está fuertemente vinculado a prácticas turísticas), mientras que desde dentro se leerían en relación con la tradición.

Masats apunta, respecto a las posibilidades de los retratos en los años 60, que "la gente era más espontánea» y se prestaba a colaborar con rodajes o proyectos fotográficos cuando se les explicaba el objetivo. Considera que, posteriormente, las personas han tenido «más conciencia de su propia identidad»», lo que ha disminuido las posibilidades de captar momentos de naturalidad. Como muestra del discurrir paralelo de las lógicas turística y fotográfica, desde el punto de vista de los tourism studies esa toma de conciencia es un punto de no retorno en el cual el visitante deberá renunciar a conocer un entorno auténtico que su sola presencia está perturbando (Cohen, 1988: 373).

El uso de jazz y de composiciones musicales contemporáneas es muy acusado en la banda sonora de "Lanzarote", y parece relacionado con la fisionomía, casi marciana o lunar, que se atribuye a la isla. Esa representación exótica se 
LUCÍA RODRÍGUEZ GARCÍA DE HERREROS

LOS DOCUMENTALES TURÍSTICOS PARA TELEVISIÓN DE RAMÓN MASATS: PRÉSTAMOS Y ESTRATEGIAS DE HIPERMEDIACIÓN

combina con ejemplos de costumbrismo, como en las imágenes tomadas en Teguise (nunca se pierde, sin embargo, el tono de la locución, tendente a lo orientalista: «sus casas, mezcla de cortijo andaluz y casona colonial, forman una arquitectura en la que se muestran extrañamente el harén y el confesionario»).

Masats recuerda que tuvo libertad para llevar aún más allá esta experimentación basada en el paisaje de Lanzarote y la música en el capítulo "Insular" de la serie Íntima armonía, en el que presentó la isla, sin texto, sobre composiciones de Luis de Pablo. Se trata de una producción que Masats define como «avanzada» a su momento televisivo, y así lo prueba el hecho de que suscitara una bronca del entonces director de TVE, Adolfo Suárez, por considerarla excesivamente intelectual.

Por otra parte, el folclore tradicional aparece en contadas ocasiones en los documentales de Masats para Conozca usted España; cuando lo hace, parece mayor el interés por la imagen sorprendente que por el examen antropológico. Por ejemplo, el momento en que, en "Lanzarote", vemos una representación de bailes tradicionales, con los correspondientes trajes locales, que tiene lugar en el interior de una de las famosas cuevas de la isla.

Pese a las citadas conexiones con el mundo de la fotografía, Masats asegura que buscaba explorar las posibilidades del medio audiovisual. Su interés por los códigos de cada medio ha sido destacado por algunos analistas de su obra audiovisual (García de Dueñas, 2000: 15). En ese sentido, Masats cuenta que le dio especial importancia al montaje, y que incluso rodaba con vistas a este: «como se daba por supuesto mi visión fotográfica o cinematográfica, yo estaba más preocupado por el montaje [...] yo exploraba más las posibilidades nuevas. Era consciente de que una cosa era la fotografía, y otra el cinels.

"Lanzarote" es un buen ejemplo de uno de los recursos de edición más llamativos de entre los utilizados por Masats: el sumario final, que, a modo de conclusión y resumen de lo ya mostrado, muestra un rápido montaje con cortes de aspectos tradicionales y turísticos (dromedarios, agricultores, juegos tradicionales, una procesión...). El estilo de cascada que el ágil ritmo imprime a estas imágenes recuerda de nuevo a la ya mencionada tendencia acumulativa de la mirada turística: inmediatamente antes de ese montaje, se ha hecho una alusión explícita a grupos de turistas montando en dromedario, pertrechados 
LUCÍA RODRÍGUEZ GARCÍA DE HERREROS

LOS DOCUMENTALES TURÍSTICOS PARA TELEVISIÓN DE RAMÓN MASATS: PRÉSTAMOS Y ESTRATEGIAS DE HIPERMEDIACIÓN

con sus cámaras fotográficas. Se trata de una fórmula que consigue enfatizar la diversidad y los contrastes que se dan en los entornos turísticos (fundamentalmente, entre huellas de lo tradicional y de la modernidad), y que fue un recurso extensamente utilizado por Masats en su posterior documental para NO-DO España de los contrastes (Ramón Masats, 1974).

\section{Conclusiones}

A través del análisis de los capítulos de Ramón Masats para Conozca usted España, se han puesto de relieve una serie de características relacionadas con el proceso de producción de dicha serie, y también de rasgos relacionados con los propios documentales: la modalidad documental, el papel de los presentadores, y los usos fotográficos, musicales y de montaje.

A partir de la conversación con el autor, se ha determinado que, en este caso, él se identifica singularmente con el trabajo en técnicas de montaje, que asocia con la especificidad del medio audiovisual. Proponemos que el recurso de los ágiles montajes, casi de atracciones, impactantes pero unidos por ejes temáticos poco específicos como "turismo", "contraste", "calle populosa" o "vida nocturna", son un ejemplo de cómo la televisión incorpora en Conozca usted España la mirada del turista (habitualmente plasmada mediante la sucesión rápida de detalles pintorescos) y algunos recursos visuales popularizados en otros medios (por ejemplo, la vida nocturna cosmopolita representada con un montaje de diferentes carteles de neón parece remitir a un cliché cinematográfico).

Es interesante relacionar esta incorporación de la mirada turística con las estrategias de preproducción explicadas por el autor, que, como se ha dicho, no eran in situ. Las representaciones turísticas tienden a beber de representaciones previas; lo interesante es ver cómo se incorporan nuevas fuentes, que aportan nuevos matices a la imagen del destino turístico.

En el caso de Masats, el autor llevó al documental turístico su bagaje como fotógrafo con inclinación al reportaje, en especial en su interés por el retrato. Se ha detectado un natural trasvase de tropos de la nueva fotografía realista de los 50-60 en la televisión de los 60 (y también de otros iconos de tradición mucho 
LUCÍA RODRÍGUEZ GARCÍA DE HERREROS

LOS DOCUMENTALES TURÍSTICOS PARA TELEVISIÓN DE RAMÓN MASATS: PRÉSTAMOS Y ESTRATEGIAS DE HIPERMEDIACIÓN

más larga), aunque fueran resignificados en un contexto de mayor optimismo y cohesión social. Sería posible preguntarse si la televisión, a menudo menos atada a servidumbres narrativas, captó con mayor agilidad ese reservorio iconográfico de lo que lo hizo el cine por aquellos años.

También resulta llamativo el efecto casi sinestésico de algunas elecciones musicales: la imagen acompañada de música pop adquiere un aura pop, la imagen acompañada de música moderna remite en cierto modo al mundo del arte contemporáneo... Esta fusión puede impregnar un paisaje o ciudad de nuevas connotaciones culturales, y hacer al espectador reflexionar sobre el contraste imagen-sonido.

Sin embargo, y de forma algo paradójica, todas estas formas de estilización no alejan al espectador de la sensación de autenticidad. Esa contradicción es típica de la relación del turismo con diferentes medios de representación y de comunicación.

Por último, hay que apuntar que la presencia de los presentadores sirvió para afianzar diferentes tesis compuestas desde el comentario, aunque esto no constituyó el interés principal de Masats. Es relevante cómo las imágenes del director se relacionan con los mensajes subyacentes en dichos guiones, mensajes casi siempre positivos, que perfilan una España que quiere ser moderna pero no renuncia a su singularidad.

Esta es, en cierto modo, una relación parecida a la que se establecerá entre las fotografías más personales de Masats y los sucesivos proyectos de folletos y libros turísticos institucionales en los que participó, sobre todo en los años 70. Como señala Alicia Fuentes Vega (2015: 121-133) a propósito de Francesc CatalàRoca, la existencia de condicionantes temáticos en los trabajos de encargo no significa que la mirada de diferentes artistas que colaboraron en proyectos del Ministerio de Información y Turismo estuviera completamente escindida entre disparos profesionales y de autor.

Por todo lo anterior, se puede argumentar que esa nueva imagen de España tiene mucho que ver con la idea de hipermediación puesto que encontró un apoyo en las constantes referencias y préstamos de unos medios a otros, referencias propuestas a menudo por profesionales jóvenes muy cotizados 
LUCÍA RODRÍGUEZ GARCÍA DE HERREROS

LOS DOCUMENTALES TURÍSTICOS PARA TELEVISIÓN DE RAMÓN MASATS: PRÉSTAMOS Y ESTRATEGIAS DE HIPERMEDIACIÓN

desde una administración que aspiraba a la modernización e internacionalización de sus mensajes. Sin embargo, es cierto que pocas veces estas referencias son tan explícitas como las que hoy resultan habituales, y pocas veces son tan visibles como para hacer al espectador reflexionar abiertamente sobre el hecho de que el conocimiento le está llegando a través de un medio, o incluso de varios. Por el contrario, sí que parece que esas referencias ayudan a crear una sensación de que la experiencia mediada es, en sí misma, experiencia de la realidad, algo que condicionará decisivamente la relación del público tanto con la industria turística como con la industria televisiva. Por eso, y de acuerdo a las definiciones ofrecidas en el marco teórico, consideramos haber analizado prácticas relacionadas con la hipermediación en un sentido psicológico (reconocimiento de que la experiencia mediada es experiencia de la realidad), aunque no tanto en un sentido epistemológico. Merecería la pena dedicar otro espacio de análisis a determinar si esto debe interpretarse como una forma consumo televisivo ingenuo, o si más bien se trata de una aceptación implícita de algunas premisas constructivistas con respecto a los medios de comunicación de masas.

\section{Bibliografía}

ANTONA, Tamara (2016), "La programación televisiva del tardofranquismo: la propaganda en las emisiones de entretenimiento y divulgación", Revista Comunicación y Medios, 34, 8-21. Disponible en: 10.5354/07191529.2016 .41633 (12-8-2021).

BOLTER, J. David, y GRUSIN, Richard A. (1999), Remediation: Understanding New Media, Cambridge: MIT Press.

CERDÁN, Josetxo (2000), "La mirada insobornable", Ramon Masats: Ibèria inèdita, Barcelona: La Fàbrica de Cinema Alternatiu, 9-12.

CERDÁN, Josetxo y FERNÁNDEZ LABAYEN, Miguel (2012), "X Films: desarrollismo y mecenazgo", Archivos de la Filmoteca, 69, abril, 168-181.

COHEN, Erik (1988), "Authenticity and commoditization in tourism", Annals of Tourism Research, 15, 371-386.

FERNÁNDEZ, Luis Miguel (2014), Escritores y televisión durante el franquismo (19561975), Salamanca: Universidad de Salamanca.

FUENTES VEGA, Alicia (2017), Bienvenido, Mr. Turismo: Cultura visual del "boom" en España, Madrid: Cátedra. 
LUCÍA RODRÍGUEZ GARCÍA DE HERREROS

LOS DOCUMENTALES TURÍSTICOS PARA TELEVISIÓN DE RAMÓN MASATS: PRÉSTAMOS Y ESTRATEGIAS DE HIPERMEDIACIÓN

FUENTES VEGA, Alicia (2015), Aportaciones al estudio visual del turismo: la iconografía del boom de España, 1950-1970, Tesis, Universidad Complutense de Madrid.

FUSTER PÉREZ, Jaime (2017), "La edición fotográfica en Ramón Masats", en Actas I Congreso Internacional sobre Fotografía, Universitat Politècnica de València. Disponible en: http://dx.doi.org/10.4995/CIFol7.2017.7055 (207-2021).

GARCÍA DE DUEÑAS, Jesús (2000), "Ramón Masats en un rincón nada neutral", en CERDÁN, J. (dir.): Ramon Masats: Ibèria inèdita, Barcelona: La Fàbrica de Cinema Alternatiu, 13-22.

LÓPEZ MONDÉJAR, Publio (2010), "España: Ramón Masats, todas las Españas", Descubrir el arte, 138, 72-75.

NICHOLS, Bill (2013), Introducción al documental, Ciudad de México: UNAM.

PALACIO, Manuel (2008), Historia de la televisión en España, Barcelona: Gedisa.

PALACIO, Manuel (2000), "Ramón Masats y la televisión", en CERDÁN, J. (dir.): Ramon Masats: Ibèria inèdita, Barcelona: La Fàbrica de Cinema Alternativ, 30-40.

PANERO GARCÍA, María Pilar (2020), "Miguel Delibes y Ramón Masats: abandono rural y documentalismo etnográfico", Siglo XXI. Literatura y Cultura Españolas, 18, 79-99. Disponible en: https://doi.org/10.24197/sxxi.18.2020.79-99 (5-7-2021).

RUEDA LAFFOND, José Carlos (2018), "La televisión, símbolo del desarrollismo franquista: Algunas claves de interpretación", Cercles. Revista d'Història Cultural, 21. Disponible en: https://doi.org/10.1344/cercles2018.21.1004 (44-2021).

RUEDA LAFFOND, José Carlos (2015), "Nosotros somos así: socialización y españolismo banal en el ocaso del Franquismo", Pensar la historia desde el siglo XXI: actas del XII Congreso de la Asociación de Historia Contemporánea, Universidad Autónoma de Madrid, 4219-4235.

SÁNCHEZ SALAS, Daniel (2000), "Filmografía", en CERDÁN, J. (dir.): Ramon Masats: Ibèria inèdita, Barcelona: La Fàbrica de Cinema Alternatiu, 41-50.

URRY, John y LARSEN, Jonas (2011), The Tourist Gaze 3.0, Londres: Sage.

\section{Recursos audiovisuales}

MASATS, Ramón (1966), "Las Ramblas", en PONS, Salvador (coord.), Conozca usted España [serie de televisión], TVE, 6-5-1966.

MASATS, Ramón (1966), "La Casa de Alba", en PONS, Salvador (coord.), Conozca usted España [serie de televisión], TVE, 17-6-1966.

MASATS, Ramón (1966), "Canto a la Andalucía musulmana", en PONS, Salvador (coord.), Conozca usted España [serie de televisión], TVE, 5-9-1966. 
MASATS, Ramón (1966), "Embajada española en Washington", en PONS, Salvador (coord.), Conozca usted España [serie de televisión], TVE, 9-121966.

MASATS, Ramón (1967), "Salamanca", en PONS, Salvador (coord.), Conozca usted España [serie de televisión], TVE, 14-9-1967.

MASATS, Ramón (1968), "Lanzarote", en PONS, Salvador (coord.), Conozca usted España [serie de televisión], TVE, 19-4-1968. 